\title{
Fine-needle aspiration biopsy of the thyroid in an area of endemic goitre: influence of restored sufficient iodine supplementation on the clinical significance of cytological results
}

\author{
Dorota Słowińska-Klencka, Mariusz Klencki, Stanisław Sporny ${ }^{1}$ and Andrzej Lewiński \\ Department of Thyroidology, Institute of Endocrinology and ${ }^{1}$ Department of Pathomorphology, Medical University of Lodz, Poland \\ (Correspondence should be addressed to A Lewiński, Department of Thyroidology, Institute of Endocrinology, Medical University of Lodz, Dr Sterling St 5 , \\ 91-425 Lodz, Poland; Email: alewin@esk.am.lodz.pl)
}

\begin{abstract}
Objective: The iodine status of the population of Poland has markedly improved over the past years. The aims of this paper were: (i) to examine the diagnostic value of fine-needle aspiration biopsy (FNAB) of the thyroid in goitre endemic regions (in conditions of improved iodine supply), and (ii) to find whether the changes in iodine supply have already influenced the clinical interpretation of cytological results. Methods: Cytological diagnoses, based on 3782 aspirates, obtained from 3572 patients during the years 1985-1999, were verified by reference to the results of postoperative examinations. The relative occurrences of selected cytological results in 1992-1999 were also compared (patients not subjected to surgery were included).

Results: We have found that the frequency of neoplastic lesions significantly decreased throughout the examined period $(P<0.02)$. The ratio of the papillary carcinoma frequency to the follicular carcinoma frequency increased from 1.7 during $1992-1993$ up to 8.0 during $1998-1999(P<0.05)$. The frequency of cytologically diagnosed chronic thyroiditis increased from 1.5\% in 1992 to $5.7 \%$ in $1999(P<0.001)$; the percentage of cytological diagnosis of 'follicular neoplasm' decreased during the same time $(P<0.001)$. The risk of malignancy significantly lowered in the cytological diagnoses of 'follicular neoplasm' from 15\% during 1985-1993 to 6\% during 1996-1999 ( $P<0.05)$.

Conclusions: The diagnostic value of FNAB during the period without proper iodine prophylaxis did not differ significantly from that during the last examined period. However, the changes in iodine supply have markedly and promptly affected the clinical significance of particular cytological results.
\end{abstract}

European Journal of Endocrinology 146 19-26

\section{Introduction}

Fine-needle aspiration biopsy (FNAB) is a quick and, at the same time, the most sensitive examination in diagnosing thyroid nodules $(1-3)$. The main advantages of FNAB are: (i) the possibility of selecting patients for prompt surgical treatment, (ii) low invasiveness, and (iii) relatively low cost of examination. Cytological examinations are used for diagnosing of not only single, hard and rapidly growing thyroid nodules but also of multinodular goitres, thyroiditis and lesions, revealed by ultrasound scanning or in scintiscan examinations $(1,2,4)$. FNABs of the thyroid are especially important in goitre endemic regions, where there are many patients with an enlarged nodular thyroid gland. In the territory of Poland, there are regions of goitre endemy of a mild and moderate degree; however, the iodine status of the population of Poland has been changing markedly over the past years (5). In 1980 , iodine prophylaxis was suddenly suspended. In consequence, the incidence of goitre and of transient thyrotrophinaemia in newborns had since then been higher $(6,7)$. Since 1986, iodised salt has been available, but still mainly uniodised salt has been in use. In the years 1992-1993, nationwide screening of children (6-13 years old) revealed abnormally low urine concentrations of iodine (with the mean value about $60 \mu \mathrm{g} / \mathrm{l}$ in our region (central Poland)) (7). Since 1995 , the increasing awareness of the problem of iodine deficiency has accounted for a gradually enhancing consumption of iodised salt. The decrease of neonatal thyrotrophin (TSH) concentrations, observed during 1993-1997, indicates a tendency towards lowering iodine deficiency in the Lodz area (the rate of neonatal TSH above $5 \mathrm{mU} / \mathrm{l}$ : 1993, 9.7\%; 1994, 6.9\%; 1995 , $2.6 \% ; 1996,1.9 \% ; 1997,2.6 \%)(6)$. Since the beginning 
of 1997, only iodised salt has been available for individual consumers in Poland (5).

The aims of this paper were: (i) to evaluate the diagnostic value of FNAB of the thyroid gland in goitre endemic regions (in conditions of improving iodine supply), and (ii) to assess whether the changes in iodine supply have already influenced the clinical interpretation of cytological results.

\section{Materials and methods}

Since 1985, more than 35000 FNABs have been performed at our Department of Thyroidology. The cytological diagnoses, based on 3782 aspirates, obtained in 1985-1999 from 3572 patients (3190 females and 382 males), subsequently treated by subtotal or total thyroidectomy, were verified by reference to results of postoperative, histopathological examinations. The mean age of the patients was $44.6 \pm 7.5$ years ( \pm s.D.), ranging from 7 to 86 years. The comparison included cases in which the interval between cytological and histological examinations was shorter than 12 months.

Biopsy of the thyroid was, in each case, preceded by palpation of the gland and by ultrascan examination. All the smears were fixed in 95\% ethanol and stained with haematoxylin and eosin. Because of non-diagnostic specimens (smears containing only blood or very few follicular cells) collected from 174 patients, cytological examinations were performed twice, and in seven patients three times. Cytological diagnoses were made by one of us (S S).

The obtained cytological results were divided into eight groups (Table 1). This classification took into account difficulties in the differentiation between follicular adenoma and carcinoma. According to many authors, the infiltration of the capsule or of blood vessels, confirmed by histopathological examination, is the only criterion by which the said conditions can be diagnosed $(2,8)$. Therefore, in cytological reports, the general term of 'follicular neoplasm' is usually used to describe such lesions. Similarly, the cytological material suspected of a follicular neoplasia of Hürthle (oxyphilic) cell type was classified as 'Hürthle cell tumour' (Group V). Cases were separated in which the cytopathologist tried to determine more precisely the benign character of the lesion by formulating the result as 'follicular neoplasm - probably adenoma' or 'Hürthle cell tumour probably adenoma' (Group IV). The lesions, unclassified into Group V but with malignancy suggested, while not allowing for an unequivocal diagnosis, were also addressed (Group VI). The cystic lesions (Group III) were classified in a separate group because the cytological material was in such cases usually scarce.

Thyroid surgeries were performed at the Department of General and Endocrine Surgery and at the 1st Department of Surgery, the Medical University of Lodz or at the Surgery Ward of the L Pasteur Municipal Hospital in Lodz. Histopathological examinations were performed at the Department of Pathomorphology, the N Copernicus District Hospital of Lodz and at the Department of Pathomorphology, the Medical University of Lodz. Surgical thyroidectomy specimens were processed by standard procedures. If necessary, immunohistochemical procedures were applied. Histopathological results were formulated according to the WHO Histological Classification of Thyroid Tumours (9). All those results were divided into the following groups: benign noninflammatory lesion, thyroiditis, benign neoplasm and malignant neoplasm (Table 2).

The sensitivity, specificity and accuracy, as well as the positive predictive value (PPV) and the negative predictive value (NPV) of the FNABs were calculated for all the verified cytological outcomes. As such calculations demanded a dichotomic classification of FNAB results, the cytological findings belonging to Groups I-IV were regarded as indications of benign lesions, which did not require surgical intervention, and those from Groups V-VII as an indication of possible malignancy, which needed surgical intervention. The biopsies from

Table 1 Groups of cytological diagnoses.

\begin{tabular}{llc}
\hline Group & \multicolumn{1}{c}{ Cytological result } & Comment \\
\hline I & Non-suspected cytologic picture without conclusion & Benign lesions \\
& Benign tumor/lesion & \\
Nodular goitre & Benign lesions \\
II & Thyroiditis (acute, subacute, chronic) & Benign lesions \\
III & Cyst & Benign lesions \\
IV & Follicular neoplasm-probably adenoma & \\
& Hürthle cell tumour-probably adenoma & Suspected lesions \\
V & Follicular neoplasm & Suspected lesions \\
VI & Hürthle cell tumour & Malignant lesions \\
VII & Unclassified suspected lesions & Non-diagnostic \\
VIII & Malignant neoplasm &
\end{tabular}


Group VIII were regarded as non-diagnostic and, as such, they were excluded from statistical analysis. Two different definitions of false positive (FP) diagnosis were applied: (i) cases either suspected of or definite for malignancy (Groups V-VII) in cytology, which were benign in histopathology (non-neoplastic or follicular adenoma), or (ii) cases either suspected of or definite for malignancy (Groups V-VII) in cytology, which were non-neoplastic in histopathology. A false negative (FN) diagnosis was defined as a benign lesion (Groups IIV) in cytology, which was malignant in histopathology. The second definition of FP results is concordant with the guidelines of the Papanicolaou Society of Cytopathology (10). Those guidelines imply cytological results being never classified as false in cases of histopathologically diagnosed benign neoplasm-follicular adenoma. Such an interpretation of false results is based on the fact that the therapy of follicular adenoma does not differ from that of hyperplastic nodule or colloid goitre, either in the extent of thyroid surgery or in further treatment and, on the other hand, the excision of goitre with follicular adenoma solves potential problems with further monitoring of follicular neoplastic lesions.

The relative frequency of particular postoperative histopathological diagnoses during the subsequent years, 1985-1999 (corresponding to the changes in iodine supply), were also compared. A similar comparison was performed for 12640 cytological diagnoses from 1992-1999 (including also the patients not submitted to surgery).

The statistical significance was evaluated by the use of the Yates corrected Chi-square test.

\section{Results}

The comparison of 3782 cytological results with 3572 histopathological findings is presented in Table 2. The diagnostic specimens were obtained by 3394 FNABs
(89.7\% of examinations). Benign lesions were found in 2819 cases $(83.0 \%$ of diagnostic specimens), suspected smears were observed in 501 cases $(14.8 \%$ of diagnostic specimens) and malignant nodules were revealed in 74 cases $(2.2 \%)$.

Neoplastic lesions were found in histopathological examinations in 1328 patients $(37.2 \%$ of all the operated patients). Benign neoplasms were revealed in $1117(31.3 \%)$ and malignant neoplasms in 211 $(5.9 \%)$ operated patients. The frequencies of malignancy were higher in patients above 65 and below 18 than the mean frequency for the entire group and equalled 10.8 and $13.5 \%$ respectively. The per cent of males was the lowest in the group with non-neoplastic lesions $(8 \%)$ and the highest in the group with malignant neoplasms $(18 \%)$.

Applying the first definition of FP results, we found true positive (TP) results in 135 cases $(3.9 \%)$, true negative (TN) in $2759(81.3 \%)$, FP in $440(12.9 \%)$ and FN in $60(1.8 \%)$. With the second definition of FP we found TP in $339(10.0 \%)$, TN in 2759 (81.3\%), FP in 236 (6.9\%) and $\mathrm{FN}$ in 60 cases (1.8\%). However, after an exclusion of cytological results such as 'follicular neoplasm' or 'Hürthle cell tumour' (Group V cases in which routine cytological examination did not allow for precise diagnosis), the number of FP results decreased to 93 $(2.7 \%)$. Taking into account the results with unequivocal diagnosis of malignancy only (Group VII), the number of FP results decreased to $10(0.3 \%)$. In one of those cases, the result of cytological examination suggested papillary carcinoma in a patient with hyalinising trabecular adenoma and twice papillary carcinoma was suggested in patients with nodular goitre without, however, any definite conclusion. In the other six cases of FP results, cytological examinations revealed a marked anisocytosis, caused by hyperthyroidism and/or thiamazole administration. In one patient with Hashimoto thyroiditis a strong anisocytosis was observed, although without intensive lymphocytic infiltration. In most cases, the FN errors were caused by the small size

Table 2 Comparison of histopathological diagnosis and cytological findings (absolute values with percentages in brackets).

\begin{tabular}{lcrrrr}
\hline \multirow{2}{*}{$\begin{array}{l}\text { Cytological result } \\
\text { (group) }\end{array}$} & \multicolumn{4}{c}{ Histopathological diagnosis } & \\
\cline { 2 - 4 } & Non-inflammatory lesion & Thyroiditis & Benign neoplasm & Malignant neoplasm & Number of biopsies \\
\hline I & $1752(46.3)$ & $28(0.8)$ & $720(19.0)$ & $47(1.2)$ & $2547(67.3)$ \\
II & $25(0.7)$ & $16(0.4)$ & $6(0.2)$ & $1(0.0)$ & $48(1.3)$ \\
III & $60(1.6)$ & 0 & $37(1.0)$ & $7(0.2)$ & $104(2.8)$ \\
IV & $68(1.8)$ & $1(0.0)$ & $46(1.2)$ & $5(0.1)$ & $120(3.1)$ \\
V & $152(4.0)$ & $14(0.4)$ & $181(4.8)$ & $49(1.3)$ & $396(10.5)$ \\
VI & $50(1.3)$ & $13(0.4)$ & $20(0.5)$ & $22(0.6)$ & $105(2.8)$ \\
VII & $6(0.2)$ & $1(0.0)$ & $3(0.1)$ & $64(1.7)$ & $74(2.0)$ \\
VIII & $178(4.7)$ & $5(0.1)$ & $179(4.7)$ & $26(0.7)$ & $388(10.2)$ \\
Number of biopsies & $2291(60.6)$ & $78(2.1)$ & $1192(31.5)$ & $221(5.8)$ & $3782(100)$ \\
Number of patients & 2170 & 74 & 1117 & 211 & 3572 \\
Female/male & $92 / 8$ & $100 / 0$ & $88 / 12$ & $82 / 18$ & $90 / 10$ \\
\hline
\end{tabular}


$(<1 \mathrm{~cm})$ of papillary carcinoma (microcarcinoma) in the thyroid gland and, in other cases, by the presence of carcinoma without any dominant nodule in the thyroid. In three cases, papillary carcinoma and, in one case, Hürthle cell carcinoma, grew up as cystic lesions.

In summary, we have determined, for the first definition of FP, the sensitivity of the cytological examination to be $69 \%$, the specificity $86 \%$, and the accuracy $85 \%$, PPV $24 \%$ and NPV $98 \%$, and for the second definition of FP the sensitivity amounted to $85 \%$, the specificity to $92 \%$, the accuracy to $91 \%$, PPV to $59 \%$ and NPV to $98 \%$.

The comparison of specific postoperative histopathological diagnoses, obtained during 1985-1999, is presented in Table 3 and Fig. 1. The frequency of neoplastic lesions significantly decreased during that period, which reflects the decrease in the frequency of follicular adenoma. Follicular carcinomas constituted $30 \%$ of all the malignant lesions in 1985-1991 and $9 \%$ of all the malignant lesions in 1998-1999; papillary carcinomas constituted $44 \%$ of the malignant lesions in the former period and $71 \%$ of the malignant lesions in the latter. The proportion of frequencies of papillary carcinoma to follicular carcinoma was 1.5 during 1985-1991, 1.7 during 1992-1993, 3.0 during 1994-1995, 4.1 during 1996-1997, and 8.0 during 1998 through 1999, being significantly higher during the last 2 years than either in the first analysed period $(P<0.02)$ and or in the second $(P<0.05)$.

Moreover, the results of FNABs of the thyroid, performed in 1992-1999, were compared (Fig. 2). We have found that the relative frequency of cytologically diagnosed chronic thyroiditis significantly increased in the analysed period. In the group of 210 patients under 18 that increase was even more pronounced than in adult patients (from 3\% in 1992 up to 16\% in 1999).

The relative frequency of cytological results, applying to 'follicular neoplasm' and 'follicular neoplasm - probably adenoma' decreased during the same time. Moreover, we found that during 1985-1993, thyroid nodules diagnosed cytologically as 'follicular neoplasm' proved to be malignant in 15\% (24 out of 156), and those diagnosed as 'Hürthle cell tumour' in 39\% of cases (9 out of 23). During 1996-1999 (after the early signs of success of the iodisation programme) the risk of malignancy in patients with an FNAB outcome regarded as an indication of follicular neoplasm decreased to $6 \%$ (9 out of 154; $P<0.02$ ), and in cases of 'Hürthle cell tumour' it was at the level of $20 \%$ (5 out of 25). The risk of malignancy in cases of not classified but suspected lesions was nearly constant in all the examined periods, amounting to $22 \%$.

We have also found that the percentage of FP results (calculated according to the first definition) increased from $10.9 \%$ during $1985-1993$ to $14.6 \%$ in the last 2 years $(P<0.05)$. The percentage of TP results decreased from $5.0 \%$ during $1985-1993$ to $3.1 \%$ in the last 2 years $(P<0.05)$. However, the diagnostic value of that examination, as assessed by the evaluation of the sensitivity and the specificity, during the period without proper iodine prophylaxis, did not significantly differ when compared with that during the last examined years. Conversely, we noticed a decrease in the PPV (from 31 to $17 \%, P<0.05$ ), following the increase of the number of FP results between the mentioned periods.

\section{Discussion}

During the past years, many reports have been published indicating the usefulness of FNAB in the diagnosis of thyroid nodules $(1-4,11-14)$. The present report presents a high number of analysed cytological examinations, verified by postoperative histopathology, and the specific iodine status of the population, which enabled an assessment of the iodine prophylaxis effects on cyto-

Table 3 The occurrence of specific postoperative histopathological diagnoses in periods between 1985 and 1999.

\begin{tabular}{|c|c|c|c|c|c|c|}
\hline \multirow[b]{2}{*}{ Histopathological diagnoses } & \multicolumn{5}{|c|}{ Number of histopathological diagnoses } & \multirow[b]{2}{*}{ Statistical significance } \\
\hline & $1985-1991$ & $1992-1993$ & $1994-1995$ & $1996-1997$ & $1998-1999$ & \\
\hline Non-neoplastic lesions & 452 & 360 & 360 & 620 & 452 & a \\
\hline Follicular adenoma & 276 & 224 & 204 & 218 & 143 & $\mathrm{~b}$ \\
\hline Hürthle cell adenoma & 12 & 10 & 9 & 12 & 9 & NS \\
\hline Papillary carcinoma & 19 & 17 & 30 & 29 & 24 & NS \\
\hline Follicular carcinoma & 13 & 10 & 10 & 7 & 3 & NS \\
\hline Hürthle cell carcinoma & 3 & 6 & 3 & 7 & 2 & NS \\
\hline Medullary carcinoma & 3 & 1 & 1 & 1 & 3 & NS \\
\hline Anaplastic carcinoma & 3 & 3 & 4 & 3 & 1 & NS \\
\hline Lymphoma & 0 & 1 & 0 & 1 & 0 & NS \\
\hline Metastases & 2 & 0 & 0 & 0 & 1 & NS \\
\hline Total & 783 & 632 & 621 & 898 & 638 & - \\
\hline
\end{tabular}

* $\mathrm{a}=P<0.05$ for 1998-1999 and 1996-1997 vs 1985-1991, 1992-1993, 1994-1995; $\mathrm{b}=P<0.01$ for $1998-1999$ and $1996-1997$ vs $1985-1991$, 1992-1993, 1994-1995. 


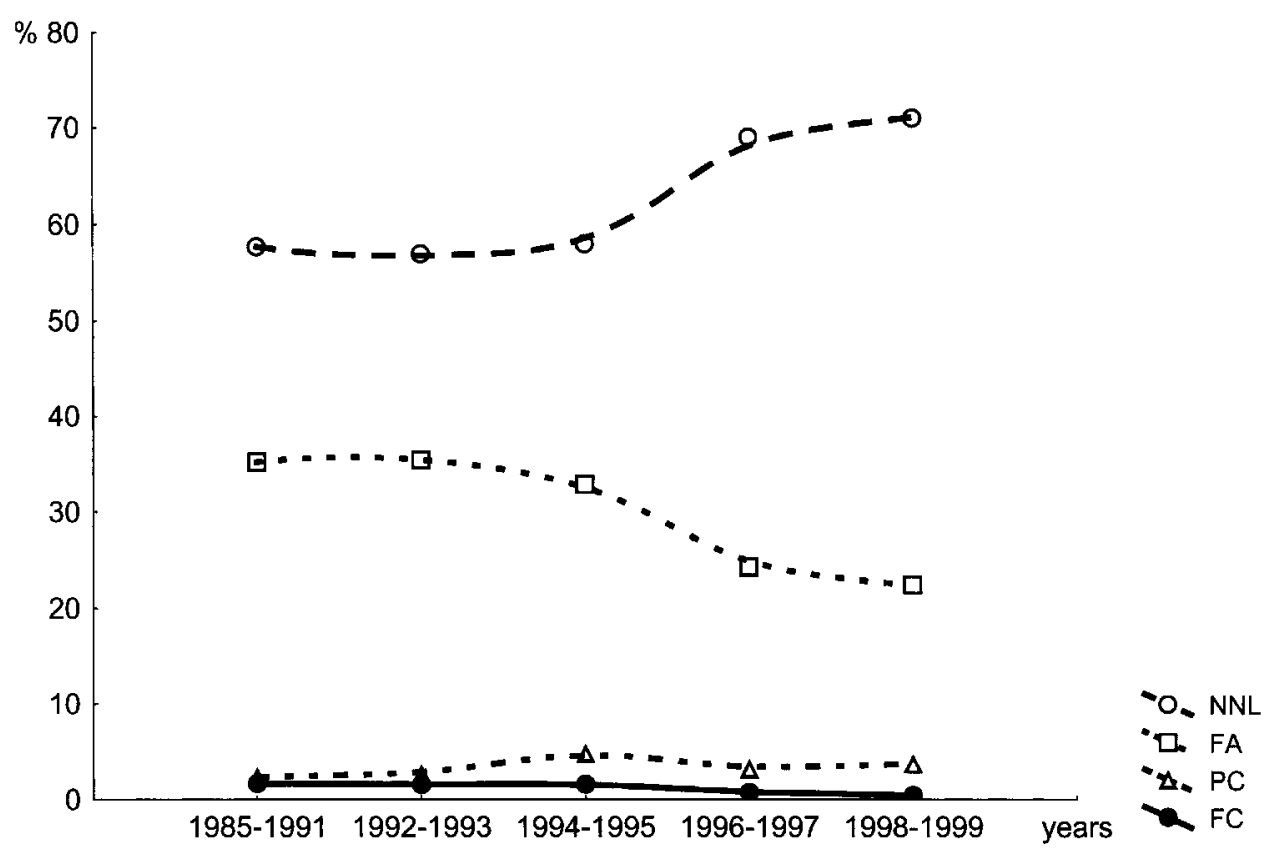

Figure 1 The occurrence of selected postoperative histopathological diagnoses in the years 1985-1999. NNL, non-neoplastic lesions, FA, follicular adenoma; PC, papillary carcinoma; FC, follicular carcinoma.

logical examinations of the thyroid. Another advantage of our material is that all the cytological examinations were performed by the same cytopathologist, experienced in thyroid cytology. Two pathologists assessed all the cases of discrepancy between cytological and postoperative histopathological examinations.
The statistical approach to the evaluation of FNAB data varies among authors (1, 2, 13, 15-17), thus making reported results hardly comparable. Some authors evaluate the sensitivity and specificity of FNAB in respect to diagnosing thyroid neoplasms (regardless of whether benign or malignant); others

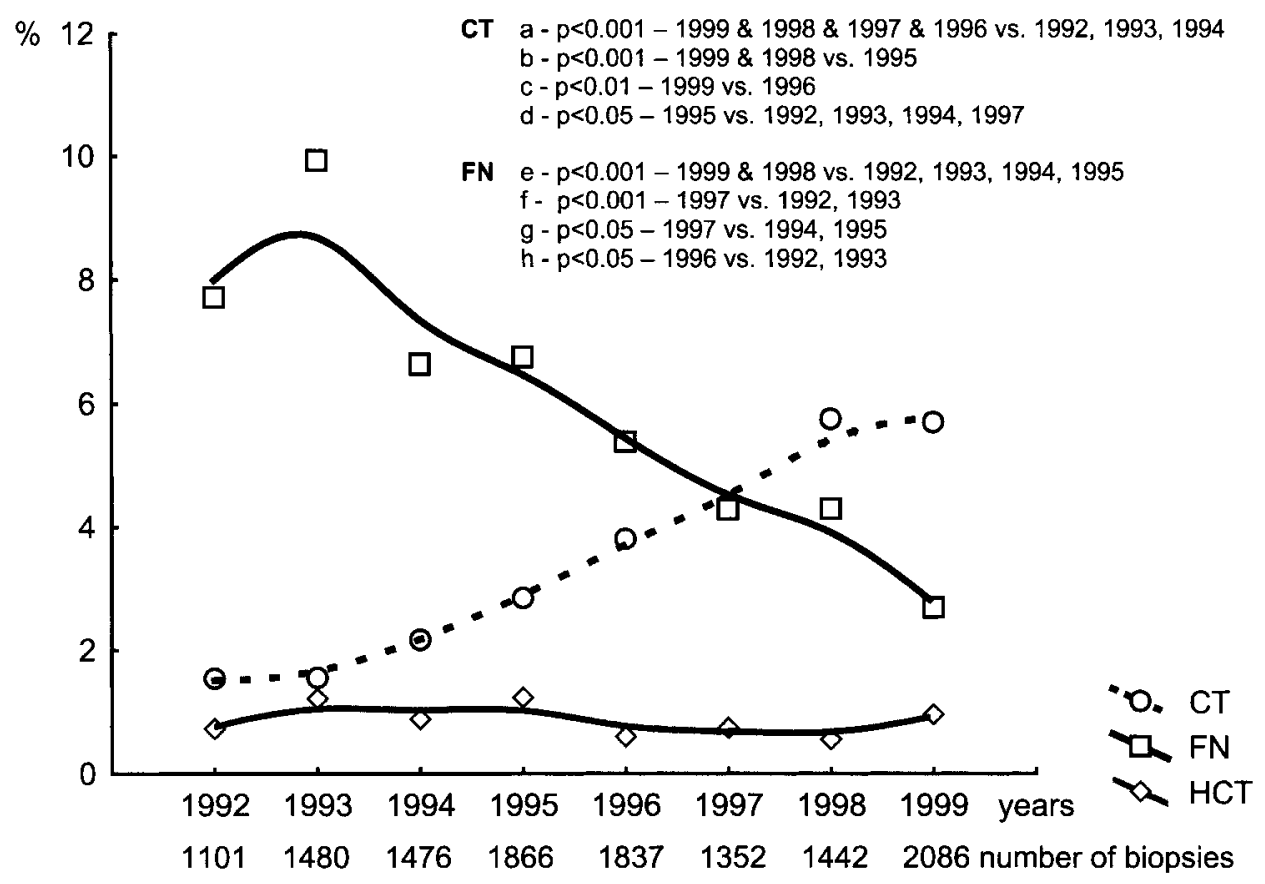

Figure 2 The occurrence of selected cytological diagnoses in the years 1992-1999 (including also the patients not subjected to surgery). CT, chronic thyroiditis; FN, follicular neoplasm; HCT, Hürthle cell tumour. Letters denote statistical significances. 
take into account malignant neoplasms only $(1,2,16-$ 18). Moreover, some authors exclude the so-called intermediate results (differently defined) from statistical analysis, while others exclude only the specific cases (e.g. exclusion from FP results, corresponding to follicular adenoma in histopathological examination) $(1,16$, 18). There is a general agreement that in regions of goitre endemy (with an increased incidence of follicular neoplasms), where FNAB is considered a screening procedure, a high number of FP results should be accepted and negative results should be optimised $(1,15,18,19)$. FN results may delay the institution of appropriate treatment. The NPV of cytological results was 98\% in the examined material. On the other hand, it should be kept in mind that the real rate of $\mathrm{FN}$ results of $\mathrm{FNAB}$ could be masked by the relatively high percentage of patients with cytologically diagnosed benign lesions who are not surgically treated, while differentiated carcinoma need not progress for years. Apart from the above mentioned facts, the high degree of correspondence between cytological and histopathological results in our whole material confirms FNAB to be a suitable screening examination, both in conditions of iodine deficiency as well as under the newly established iodine prophylaxis.

We have found that $10.8 \%$ of biopsies were non-diagnostic. According to the data of other authors, the percentage of non-diagnostic specimens was between 5 and $20 \%(2,11,12)$. Such a variation reflects the lack of standard criteria for classifying smears as diagnostic ones. Some authors require five or six groups of wellpreserved, well-visualised follicular cells, with each group containing ten or more cells (13). Sidawy et al. (2) have correctly indicated that the classification of a smear as diagnostic could depend on the cytologist's experience and the type of lesion.

FNAB enables unequivocal diagnosis in the following cases: anaplastic carcinoma, papillary carcinoma, de Quervain's thyroiditis and acute thyroiditis. However, in cases of papillary microcarcinoma (the diameter of which is a few millimetres only) ultrasound examination usually does not visualise the lesion and, consequently, FNAB examination cannot be effective. Thus, an improvement in the effectiveness of histopathological examinations, in respect to revealing papillary microcarcinomas, can lead to an increase in the percentage of FN results. Moreover, in smears with the follicular variant of papillary carcinoma, the characteristic features of papillary carcinoma (nuclear grooves and intranuclear inclusions) are visible in a minority of cells only. Thus, such smears can be misinterpreted as follicular neoplasm. Fortunately, this limitation of thyroid cytology is not critical (usually does not influence therapeutic decisions) (2).

FNAB does not allow for differentiation among certain forms of nodular goitre, follicular adenoma and highly differentiated follicular carcinoma of the thyroid $(1-3,8,10)$. This problem is the main limitation of
FNAB diagnostics, especially in endemic regions (2022). Consequently, in clinical practice, the cytological diagnoses of 'follicular neoplasm' and, especially, of 'Hürthle cell tumour' are frequently regarded as an indication for surgical treatment. The consideration of the above suspicion-raising results of cytological examination, as an indicator of possible malignancy, results in a dramatic increase of FP results (as classified by the first definition). That percentage was $12.9 \%$ in our material, remaining within the range of $1-18 \%$ in the reports of other authors $(2,11-13)$. After the exclusion of cytological results called 'follicular neoplasm' and 'Hürthle cell tumour', the number of FP results decreased to $2.7 \%$.

We have found that the implementation of iodine prophylaxis was accompanied by a decreased number of cytological diagnoses of follicular neoplasm. In spite of that, the number of FP results (calculated according to the first definition) increased in the same time. That resulted from the simultaneous decrease in histopathologically diagnosed follicular neoplasms. Malignant neoplasms were revealed only in $6 \%$ of all the cases of 'follicular neoplasm' observed during the last 2 years. The risk of malignancy significantly lowered in cases of that cytological outcome. Cytologically diagnosed follicular neoplasms relatively more frequently corresponded to hyperplastic nodules in nodular goitre or to follicular adenomas in the latter examined period.

From the clinical point of view, the assessment of carcinoma in patients with cytologically suspected lesion seems to be especially important. The reported frequency of malignancy with suspected (intermediate) smears ranges from about 15\% to more than 30\% (11, 12). However, the risk of malignancy with intermediate cytology also depends on the definition of the term 'intermediate' (2). In our material, the risk of malignancy in cases of unclassified suspected lesions (Group VI) was nearly constant in all the examined periods and equalled $22 \%$.

There is general agreement that endemic goitre areas are associated with the elevated risk of follicular and undifferentiated thyroid carcinomas, while iodine-rich areas are associated with the enhanced risk of the papillary type (23-27). In our study, while the number of follicular neoplasms decreased in the analysed periods, the occurrence of papillary carcinoma, relative to follicular carcinoma, increased. Similarly, Harach \& Williams (28) reported that the ratio of papillary to follicular carcinoma rose from 1.7:1 in the first analysed period (15 years, including only 5 years before iodine prophylaxis) to $3.1: 1$ in the second period (16 consecutive years). Our data do not prove any causal relationship between iodine intake and the described changes in histopathological and cytological diagnoses; nevertheless, in our opinion, variations in iodine supply may be the most important factor affecting such diagnoses.

The primary role of iodine supplementation in the prevention and treatment of endemic goitre has firmly 
been established (29). Moreover, epidemiological studies have demonstrated a relationship between the introduction of iodine prophylaxis and the type of thyroid carcinoma $(30,31)$. However, the occurrence of that process was rather unexpected during such a relatively short time of observation. The frequency of a neonatal TSH level above $5 \mathrm{mU} / \mathrm{l}$, the most important early sign of success in iodisation programmes, was shown to be less than 3\% in 1995 in the Lodz area (6). It should be remembered that the observed increase in the relative frequency of papillary carcinoma could be partly attributed to the improved effectiveness of routine histopathological examinations, resulting in more frequent revealing of papillary microcarcinoma and in proper diagnosing of the follicular variant of papillary carcinoma without erroneous classification of such tumours into follicular carcinomas (32). The data from Sweden did not suggest any enhancing effect of iodisation on papilllary carcinoma, since the increases in the incidence of such type of cancer were similar in both iodine-deficient and iodine-sufficient areas (33). Moreover, the correction of iodine deficiency rates virtually coincided in highly developed countries with the spread of thyroid ultrasound and biopsy, which have made diagnosis of clinically silent thyroid carcinoma more frequent. Thus, even though the incidence of thyroid carcinoma rose, the prognosis has significantly improved due to a shift towards differentiated forms of thyroid carcinomas that are diagnosed at earlier stages (34).

On the other hand, we have observed that the occurrence of autoimmune stigmata in smears was significantly higher during the last years than in earlier periods. An analysis of the results of antithyroid antibody assays should be performed to formulate conclusions with regards to the changes in the occurrence of chronic thyroiditis. However, similar observations were reported in a study from Greece by Doufas et al. (35) and from Argentina by Harach \& Williams (28) (although during much longer intervals before and after introduction of iodine prophylaxis). Autoimmune thyroid diseases are more common in iodine-sufficient areas than in areas with low iodine intake $(31,36)$, but the true incidence of Hashimoto thyroiditis has not yet been clearly demonstrated with the aid of epidemiological methods (29). It is believed that iodine intake might modulate the activity (and/or clinical expression) of thyroid autoimmune diseases in genetically susceptible individuals, but there is no evident proof that the amount of iodine intake (at least when in the range between iodine deficiency and full physiological doses) is involved in the de novo triggering of thyroid autoimmunity $(37,38)$. However, despite the underlying mechanism, the possibility of marked anisocytosis of follicular cells in cases of chronic thyroiditis could lead to an increased number of FP results of FNAB. Cytological examinations provide good results in the diagnosis of Hashimoto thyroiditis, under the conditions of the cytologist being aware of laboratory results and of relevant findings on physical examination.

Summing up, while clinically interpreting the results of cytological examination, the iodine status of examined population should be considered. Changes in the iodine status of a given population promptly influence the clinical significance of particular cytological results. In such circumstances, special attention is advised from both the cytologist and the thyrologist. In regions with newly established iodine prophylaxis, the risk of cytologically determined follicular neoplasm being a malignant tumour is lower, which is in contrast to regions with constant and high iodine intake, where nodules in the thyroid are uncommon and thus more frequently malignant. On the other hand, in such regions, the reactive anisocytosis of thyroid follicular cells in the course of Hashimoto thyroiditis is more likely to prompt surgical intervention.

\section{Acknowledgements}

The study has been supported by the Medical University of Lodz, grant No. 502-11-484.

\section{References}

1 Leonard N \& Melcher DH. To operate or not to operate? The value of fine needle aspiration cytology in the assessment of thyroid swellings. Journal of Clinical Pathology $199750941-943$.

2 Sidawy MK, Del Vecchio DM \& Knoll SM. Fine-needle aspiration of thyroid nodules. Correlation between cytology and histology and evaluation discrepant cases. Cancer Cytopathology $1997 \mathbf{8 1}$ 253-259.

3 Słowińska D, Lewiński A, Sporny S, Klencki M \& Gesing A. Comparative analysis of fine needle aspiration biopsy results performed in the Laboratory of Thyroidology, University School of Medicine in Łódź in 1985-1991 with results of postoperative histopathologic examinations. Endokrynologia Polska - Polish Journal of Endocrinology $1992 \mathbf{4 3} 423-436$.

4 Kini SR. Adequacy, reporting system and cytopreparatory technique. In Thyroid (Guides to Clinical Aspiration Biopsy), edn 2, ch 3, pp 13-18. New York, NY: Igaku-Shoin, 1996.

5 Szybiński Z, Delange F, Lewiński A, Podoba J, Rybakowa M \& Wasik R. A programme of iodine supplementation using only iodised household salt is efficient - the case of Poland. European Journal of Endocrinology $2001144331-337$.

6 Pniewska-Siark B, Bobeff I, Małagocka-Wojciechowska E, Ligocka E, Zarzycki B \& Zarzycki J. Neonatal screening program for congenital hypothyroidism as a monitoring system of iodine deficiency in the Łódź Macroregion. Endokrynologia Polska - Polish Journal of Endocrinology $1998 \mathbf{4 9}$ (Suppl 1) 77-83.

7 Lewiński A, Tomaszewski W, Klencki M, Wajs E, Karbownik M, Słowińska-Klencka D, Skowrońska-Jóźwiak E, Biliński P, Brzeziński J, Sewerynek E, Rybicka I, Kułak J, Kurowska A \& Małolepsza A. Occurrence of goiter in relation to iodine deficiency in school children from city of Łódź, the Łódź metropolitan area and Piotrków, Sieradz, Płock, Włocławek, Radom and Skierniewice voivodships. (Łódź coordination center). Endokrynologia Polska - Polish Journal of Endocrinology $199344271-285$.

8 Li Volsi VA \& Asa SL. The demise of follicular carcinoma of the thyroid gland. Thyroid $19944233-236$.

9 Hedinger CH, Williams D \& Sobin L. The histological typing of thyroid tumors. In International Histological Classification of 
Tumours, No. 11, edn 2. Berlin, Heidelberg, New York, London, Paris, Tokyo: World Health Organization, Springer Verlag 1988.

10 Guidelines of the Papanicolaou Society of Cytopathology for the examination of fine-needle aspiration specimens from thyroid nodules. Diagnostic Cytopathology $19961584-89$.

11 Al-Sayer HM, Krukowski ZH, Williams VM \& Matheson NA. Fine needle aspiration cytology in isolated thyroid swellings: a prospective two year evaluation. British Medical Journal 1985 290 1490-1492.

12 Altavilla G, Pascale M \& Nenci I. Fine needle aspiration cytology of thyroid gland diseases. Acta Cytologica $199034251-256$.

13 Gharib H \& Goellner JR. Fine-needle aspiration biopsy of the thyroid: an appraisal. Annals of Internal Medicine $1993 \mathbf{1 1 8}$ 282-289.

14 Ravinsky E \& Safneck JR. Fine needle aspirates of follicular lesions of the thyroid gland. The intermediate-type smear. Acta Cytologica $199034813-820$

15 Musgrave YM, Davey DD, Weeks JA, Banks ER, Rayens MK \& Ain KB. Assessment of fine-needle aspiration sampling technique in thyroid nodules. Diagnostic Cytopathology 199818 76-80.

16 La Rosa GL, Belfiore A, Giuffrida D, Sicurella C, Ippolito O, Russo G \& Verneri R. Evaluation of the fine needle aspiration biopsy in the preoperative selection of cold thyroid nodules. Cancer 199167 2137-2141.

17 Lioe TF, Elliott H, Allen DC \& Spence AJ. A 3-year audit of thyroid fine needle aspirates. Cytopathology 19989 188-192.

18 Cap J, Ryska A, Rehorkova P, Hovorkova E, Kerekes Z \& Pohnetalova D. Sensitivity and specificity of the fine needle aspiration biopsy of the thyroid: clinical point of view. Clinical Endocrinology $199951509-515$

19 Schmid KW. Clinicopathologic management of tumors of the thyroid gland in an endemic goiter area; combined use of preoperative fine needle aspiration biopsy and intraoperative frozen section. Acta Cytologica 198933 27-30.

20 Belfiore A \& La Rosa GL. Cancer risk in patients with cold thyroid nodules: relevance of iodine intake, sex, age, multinodularity. American Journal of Medicine 199293 363-369.

21 Dralle H. Metaanalysis of thyroid cancer risk in patients with cold thyroid nodules and multinodular goiter. Experimental and Clinical Endocrinology 1993101 109-117.

22 Mikosch P, Gallowitsch HJ, Kresnik E, Jester J, Wurtz FG, Kerschbaumer K, Unterweger O, Dinges HP \& Lind P. Value of ultrasound-guided fine-needle aspiration biopsy of thyroid nodules in an endemic goiter area. European Journal of Nuclear Medicine $20002762-69$.

23 Williams ED, Doniach I, Bjarnason O \& Michie W. Thyroid cancer in an iodine rich area: a histopathological study. Cancer 197739 215-222.

24 Hofstadter F. Frequency and morphology of malignant tumours of the thyroid before and after the introduction of iodine-prophylaxis. Virchows Archiv A: Pathological Anatomy and Histology 1980385 $263-270$.
25 Williams ED. Mechanisms and pathogenesis of thyroid cancer in animals and man. Mutation Research 1995333 123-129.

26 Hay ID. Papillary thyroid carcinoma. Clinical Endocrinology and Metabolism Clinics of North America 199019 545-576.

27 Franceschi S, Levi F, Negri E, Facina A \& La Vecchiio C. Diet in thyroid cancer: a pooled analysis of four European case control studies. International Journal of Cancer $1991 \mathbf{4 8} 395-398$.

28 Harach HR \& Williams ED. Thyroid cancer and thyroiditis in the goitrous region of Salta, Argentina, before and after iodine prophylaxis. Clinical Endocrinology 199543 701-706.

29 Delange F \& Lecomte P. Iodine supplementation: benefits outweigh risks. Drug Safety 200022 89-95.

30 Feldt-Rasmussen U. Iodine intake and prevalence and types of thyroid carcinoma. In The Thyroid and Iodine. Eds J Nauman, D Glinoer, LE Braverman, U Hostalek, Stuttgart, New York: Schattauer $75-78,1996$.

31 Lind P, Langsteger W, Molnar M, Gallowitsch HJ, Mikosch P \& Gomez I. Epidemiology of thyroid diseases in iodine sufficiency. Thyroid $1998 \mathbf{8} 1179-1183$.

32 Franceschi S. Iodine intake and thyroid carcinoma - a potential risk factor. Experimental and Clinical Endocrinology and Diabetes $199810638-44$.

33 Pettersson B, Coleman MP, Ron E \& Adami HO. Iodine supplementation in Sweden and regional trends in thyroid cancer incidence by histopathologic type. International Journal of Cancer $1996 \mathbf{6 5}$ 13-19.

34 Bacher-Stier C, Riccabona G, Totsch M, Kemmler G, Oberaigner W \& Moncayo R. Incidence and clinical characteristics of thyroid carcinoma after iodine prophylaxis in an endemic goiter country. Thyroid $19777733-741$.

35 Doufas AG, Mastorakos G, Chatziioannou S, Tseleni-Balafouta S, Piperingos G, Boukis MA, Mantzos E, Caraiskos CS, Mantzos J, Alevizaki M \& Koutras DA. The predominant form of non-toxic goiter in Greece is now autoimmune thyroiditis. European Journal of Endocrinology $1999 \mathbf{1 4 0} 505-511$.

36 Boukis MA, Koutras DA, Souvatzoglou A \& Evangelopoulou A. Thyroid hormone and immunological studies in endemic goiter. Journal of Clinical Endocrinology and Metabolism $1983 \mathbf{5 7}$ 859-862.

37 Rose NR, Saboori AM, Rasooly L \& Burek L. The role of iodine in autoimmnume thyroiditis. Critical Reviews in Immunology 1997 $17511-517$

38 Mariotti S, Loviselli A, Cambosu A, Velluzi F, Atzeni F, Martino E \& Bottazzo G. The role of iodine in autoimmune thyroid disease in humans. In The Thyroid and Iodine, pp 156-168. Eds J Nauman, D Glinoer, LE Braverman \& U Hostalek. Stuttgart, New York: Schattauer, 1996.

Received 5 January 2001

Accepted 31 August 2001 